\title{
Involvement of UCP3 in mild uncoupling and lipotoxicity
}

Citation for published version (APA):

Hoeks, J., Hesselink, M. K., \& Schrauwen, P. (2006). Involvement of UCP3 in mild uncoupling and lipotoxicity. Experimental Gerontology, 41(7), 658-826. https://doi.org/10.1016/j.exger.2006.02.005

Document status and date:

Published: 01/01/2006

DOI:

10.1016/j.exger.2006.02.005

Document Version:

Publisher's PDF, also known as Version of record

Document license:

Taverne

Please check the document version of this publication:

- A submitted manuscript is the version of the article upon submission and before peer-review. There can be important differences between the submitted version and the official published version of record.

People interested in the research are advised to contact the author for the final version of the publication, or visit the DOI to the publisher's website.

- The final author version and the galley proof are versions of the publication after peer review.

- The final published version features the final layout of the paper including the volume, issue and page numbers.

Link to publication

\footnotetext{
General rights rights.

- You may freely distribute the URL identifying the publication in the public portal. please follow below link for the End User Agreement:

www.umlib.nl/taverne-license

Take down policy

If you believe that this document breaches copyright please contact us at:

repository@maastrichtuniversity.nl

providing details and we will investigate your claim.
}

Copyright and moral rights for the publications made accessible in the public portal are retained by the authors and/or other copyright owners and it is a condition of accessing publications that users recognise and abide by the legal requirements associated with these

- Users may download and print one copy of any publication from the public portal for the purpose of private study or research.

- You may not further distribute the material or use it for any profit-making activity or commercial gain

If the publication is distributed under the terms of Article $25 \mathrm{fa}$ of the Dutch Copyright Act, indicated by the "Taverne" license above, 


\title{
Involvement of UCP3 in mild uncoupling and lipotoxicity
}

\author{
Joris Hoeks ${ }^{a}$, Matthijs K.C. Hesselink ${ }^{b}$, Patrick Schrauwen ${ }^{\text {a,* }}$

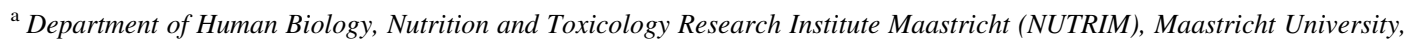 \\ P.O. Box 616, NL-6200 MD, Maastricht, The Netherlands \\ ${ }^{\mathrm{b}}$ Department of Movement Sciences, Nutrition and Toxicology Research Institute Maastricht (NUTRIM), Maastricht University, \\ Maastricht, The Netherlands
}

Received 10 November 2005; accepted 14 February 2006

Available online 27 March 2006

\begin{abstract}
Although vital to life, mitochondria are also the major source of ROS production, which may have unwanted detrimental effects on DNA, RNA and protein structures Therefore, mitochondria must exhibit well-developed mechanisms to regulate its ROS production. One such mechanism might be mild uncoupling of the mitochondrial respiratory chain, thereby lowering the proton gradient across the inner mitochondrial membrane and directly lowering ROS production. Mitochondrial uncoupling proteins have been shown to possess mild uncoupling activity and may therefore be important regulator of mitochondrial ROS production. The skeletal muscle isoform of the uncoupling protein family, UCP3, seems to be specifically active under conditions of high fatty acid availability. Although the exact function of UCP3 is not yet unravelled, UCP3 is activated by lipid peroxides and suggested to export fatty acid anions and/or peroxides from the mitochondrial matrix, thereby specifically protecting fatty acids from ROS-induced oxidative damage. Protein levels of UCP3 are reduced with aging and in the (pre)-diabetic state, both conditions characterized by increased levels of oxidative damage to lipids and proteins and reduced mitochondrial function. Whether UCP3 is causally related to mitochondrial dysfunction and is essential in the prevention and treatment of lipid-induced mitochondrial dysfunction requires further study.

(C) 2006 Elsevier Inc. All rights reserved.
\end{abstract}

Keywords: Mitochondrial uncoupling protein; Lipotoxiciy; UCP3, Diabetes; ROS

\section{Introduction}

In addition to capturing energy in the form of adenosine triphosphate (ATP), mitochondria are also a major source of reactive oxygen species (ROS). Reactive oxygen species have a very short half-life and can react rapidly with mitochondrial DNA and proteins, inducing so-called oxidative damage (Sastre et al., 2000). In particular, membrane lipids and fatty acids are prone to oxidation by ROS, resulting in the formation of cytotoxic and highly reactive lipid peroxides. In turn, these lipid peroxides can also induce damage to the mitochondrial machinery. Therefore, accumulation of fatty acids in the vicinity of the mitochondrial matrix, where oxidative processes take place, makes them prone to peroxidation, which eventually may contribute to damage to mitochondrial proteins with a reduced oxidative capacity as a consequence. Formation

\footnotetext{
* Corresponding author. Tel.: +31 43 3881502; fax: + 31433670976.

E-mail address: p.schrauwen@hb.unimaas.nl (P. Schrauwen).
}

0531-5565/\$ - see front matter (c) 2006 Elsevier Inc. All rights reserved. doi:10.1016/j.exger.2006.02.005 of ROS and peroxidation of lipids induced by ROS can occur under multiple (patho)physiological conditions, including type 2 diabetes mellitus.

Type 2 diabetic patients are characterized by a reduced fat oxidative capacity (Kelley and Simoneau, 1994) and increased plasma free fatty acid levels (McGarry, 2002). In addition, skeletal muscle of type 2 diabetic patients is characterized by increased levels of intramyocellular fat (Perseghin et al., 1999) and lipid peroxides (Russell et al., 2003). Very interestingly, Kelley et al., (2002) reported that mitochondria of type 2 diabetic patients had reduced capacity of the electron transport chain (as measured by NADH: $\mathrm{O}_{2}$ oxidoreductase activity) and reduced citrate synthase activity. To investigate a potential explanation for the diminished oxidative capacity, Kelley et al., (2002) also examined mitochondrial morphology and found that mitochondria from type 2 diabetic patients were damaged, smaller, and that mitochondrial size correlated positively with insulin sensitivity. In addition, Petersen et al., (2004) showed reduced mitochondrial function in skeletal muscle of insulinresistant offspring of type 2 diabetic patients in parallel with elevated IMCL levels. Also in the elderly, it was shown that muscular lipid accumulation is related to mitochondrial 
dysfunction and insulin resistance (Petersen et al., 2003), and aging is associated with accumulation of ROS-induced mutations in control sites of mitochondrial DNA replication (Michikawa et al., 1999). Together, these results suggest that lipid accumulation in muscle cells, as observed in type 2 diabetes mellitus and with aging (Perseghin et al., 1999; Petersen et al., 2003), could impair mitochondrial oxidative capacity due to lipid peroxidation-induced damage to mitochondria. In turn, the reduced mitochondrial oxidative capacity would further exacerbate the storage of lipids inside the muscle cell and reduce insulin sensitivity. If fatty acid entrance into the mitochondrial inner membrane and/or matrix is indeed harmful to mitochondria, the question is how mitochondria are protected against ROS-related lipotoxicity.

\section{Mild uncoupling hypothesis}

When the mitochondrial membrane potential is high because of increased export of protons from the mitochondrial matrix across the inner mitochondrial membrane the production of superoxide (the primary ROS produced) in the mitochondrial electron-transport chain increases as a result of increased non-specific single-electron reductions of molecular oxygen at complexes I and III (Turrens, 1997). In isolated mitochondria, the rate of ROS production is dependent on the metabolic state: it decreases in the transition from state 4 to state 3 and is inversely related to the coupling between respiratory chain and ATP synthesis (Boveris et al., 1972). In other words, superoxide production is dependent on the proton gradient across the mitochondrial inner membrane. Important work in this field has been performed by Skulachev (1996) who showed that mild uncoupling may be effective in lowering mitochondrial ROS production. Mild uncoupling implies a limited increase in proton conductance of the inner mitochondrial membrane so that proton motive force is slightly lowered, reducing the risk of ROS production and respiration rate is slightly increased, but ATP can still be produced. Such mild uncoupling would be a way to lower mitochondrial ROS production and prevent lipid peroxidation and subsequent mitochondrial damage in skeletal muscle. In 1997, the relevance of controlled mild uncoupling was extended to muscle physiology due to the discovery of a so-called uncoupling protein (called UCP3) that is present in skeletal muscle mitochondria. Shortly after its discovery it was suggested that UCP3 might contribute to the reduction of ROS by mediating mild uncoupling. The question arises if UCP3-induced mild uncoupling is indeed present and, more importantly, if and to what extent UCP3 mediated mild uncoupling may contribute to modulation of ROS-induced lipid peroxidation and mitochondrial damage.

\section{UCP3 and ROS production}

Brand and colleagues were the first to propose that UCP3 could be involved in lowering ROS production in skeletal muscle mitochondria through mild uncoupling. More importantly they suggested that superoxide could function as an activator of UCP3 (Echtay et al., 2002), thereby providing a negative feedback loop between ROS production and UCP3 activation. To test this hypothesis in more detail, Echtay et al., (2002) incubated rat skeletal muscle mitochondria in a superoxide- and hydrogen peroxide-generating model (by adding xanthine + xanthine oxidase) and reported an increase in proton conductance, an effect that could be prevented by the addition of GDP (an established inhibitor of UCPs) or superoxide dismutase. Addition of external hydrogen peroxide did not affect GDP-sensitive uncoupling (Echtay et al., 2002). Thus, it seemed that superoxide was responsible for the observed increase in proton conductance, which was sensitive to GDP, suggesting UCP3-mediated uncoupling. In line with this, skeletal muscle mitochondria from $\mathrm{UCP}^{-1-}$ mice did not show superoxide-induced uncoupling that could be inhibited by GDP, in contrast to wild-type mice. Jointly, these observations indicate that the uncoupling was indeed mediated by UCP3 (Echtay et al., 2002).

In further support of the possible role for UCP3 in the production of reactive oxygen species, it was shown that aconitase activity (an enzyme in the citric acid cycle), which inversely correlates with intracellular ROS production, was significantly decreased in $\mathrm{UCP} 3^{-1-}$ mice, indicating an increased ROS production in vivo in these mice (Vidal-Puig et al., 2000).

In ongoing studies, Brand and colleagues established that superoxide-induced activation of UCP3 is actually mediated via lipid peroxide intermediates (Echtay et al., 2003). Thus, reactive oxygen species interact with polyunsaturated fatty acids, forming reactive aldehydes such as 4-hydroxy-2-nonenal (4HNE). Echtay et al. (2003) revealed that hydroxynonenal was, like superoxide, able to increase proton conductance in isolated skeletal muscle mitochondria from rats in a GDP sensitive manner, indicating that UCP3-mediated uncoupling indeed occurred. In addition, the hydroxynonenal-induced increase in proton conductance was significantly blunted in mitochondria from $\mathrm{UCP} 3^{-1-}$ mice compared to wild type mitochondria, and GDP did not affect this increase in proton conductance (Echtay et al., 2003), again underscoring the importance of UCP3 in modulating ROS by mild uncoupling.

Taken together, there is in vitro evidence that UCP3 can be activated by superoxides and lipid peroxides suggesting a negative feedback loop between ROS production, lipid peroxidation and mitochondrial uncoupling induced by UCP3. However, deduced from physiological data on the regulation of UCP3 content, as well as the distribution of UCP3 in muscle with varying oxidative capacity, limitation of ROS production via UCP3-induced mild uncoupling seems to be restricted to conditions of altered fatty acid metabolism.

\section{UCP3 may prevent lipid peroxidation by acting as a fatty acid anion exporter}

An alternative way to protect fatty acids in the vicinity of the mitochondrial matrix against ROS-induced peroxidation is by removing these fatty acids away from the mitochondrial matrix. The increased levels of lipid peroxidation observed in 
type 2 diabetes mellitus are accompanied by increased muscular fat content, suggesting that especially fatty acids that are in excess are prone to become peroxidized. In that context, it is important to note that the regulation of UCP3 mRNA and protein content is very strongly associated with the balance between muscular fatty acid availability and oxidative capacity. Hence, UCP3 is up-regulated or high when fatty acid supply to the mitochondria is likely to exceed the capacity to oxidize these fatty acids (high-fat feeding, fasting, acute exercise, lipid infusion, type 2 muscle fibres) and downregulated or low when oxidative capacity is high or improved (weight reduction, endurance training, type 1 muscle fibres). To allow oxidation, sarcoplasmic fatty acids are subsequently esterified into fatty acyl-CoA by fatty acyl-CoA synthetase (ACS), an enzyme associated with the outer mitochondrial membrane. This fatty acyl-CoA crosses both mitochondrial membranes through the carnitine shuttle system and is reconverted into fatty acyl-CoA inside the matrix where they enter the $\beta$-oxidation pathway. However, when cytosolic levels of fatty acids increase inside muscle cells due to a mismatch between fat supply and oxidation capacity, the load of fatty acids on the mitochondria would drive neutral non-esterified fatty acids across the outer mitochondrial membrane, which is easily permeable to fatty acids. Although the inner mitochondrial membrane provides a barrier for non-esterified fatty acids, neutral non-esterified fatty acids can partition into the phospholipids bilayer and reach the mitochondrial matrix by flip-flop (Hamilton and Kamp, 1999). Once at the matrix side of the inner mitochondrial membrane, these neutral nonesterified fatty acids become deprotonated due to the proton gradient present across the inner mitochondrial membrane, leaving a proton and a fatty acid anion. Because the mitochondrial matrix lacks the enzyme to convert this fatty acid into fatty acyl-CoA and because of its anionic nature, the fatty acid can neither undergo $\beta$-oxidation nor flip-flop back to the intermembrane space (Jezek et al., 1994). As mentioned before, within the mitochondrial matrix or in the inner leaflet of the inner mitochondrial membrane, these fatty acids are prone to peroxidation as the mitochondrial matrix is the major site of ROS production. This would result in highly reactive lipid peroxide products, which may exert recognised detrimental effects to mitochondrial DNA, RNA and proteins.

Based on the fact that UCP3 (at mRNA and protein level) is rapidly induced under experimental conditions (in vitro as in vivo) when the above process is likely to occur, and because UCP3 was shown to be able to transport fatty acid anions, we postulated in 2001 the hypothesis that UCP3 is involved in the outward translocation of fatty acid anions that can enter the mitochondria during lipid oversupply, thereby preventing accumulation and peroxidation of non-metabolizable fatty acids inside the mitochondrial matrix or the inner leaflet of the mitochondrial membrane (Schrauwen et al., 2001a). This hypothesis is in fact an extension of the earlier fatty acid cycling hypothesis by Skulachev (1991), which explains the mechanism of uncoupling action by UCPs. According to the latter hypothesis, UCP facilitates a fatty acid anion transport across the inner mitochondrial membrane. When these fatty acid anions reach the outer leaflet of this phospholipids bilayer, they pick up a proton from the intermembrane space and return to the inner leaflet of the inner mitochondrial membrane by the so-called flip-flop mechanism. In the inner leaflet, the fatty acids are deprotonated again, releasing a proton in the mitochondrial matrix and thereby lowering the proton gradient (Skulachev, 1991). In our model we propose that the physiological relevance of this fatty acid cycling is not mitochondrial uncoupling per se, but rather the prevention of the accumulation of non-metabolizable fatty acid anions in the inner leaflet of the mitochondrial membrane by exporting the fatty acid anions from the inner leaflet until they can leave the mitochondrial inner membrane once the cytosolic fatty acid levels decrease. Please also note, however, that by exporting fatty acid anions, UCP3 also induces 'mild uncoupling' thus limiting mitochondrial ROS production.

In support of our hypothesis, we showed that inhibition of mitochondrial fatty acid oxidation, through inhibition of CPT1 by etomoxir, resulted in a very rapid induction of UCP3 protein levels (Schrauwen et al., 2003). In addition, we showed that a high-fat diet, based on medium-chain triacylglycerols, does not alter muscular UCP3 protein levels, in contrast to a high-fat long-chain triacylglycerol diet, which caused a $\sim 2$-fold increase in UCP3 protein (Hoeks et al., 2003). Medium-chain fatty acids (MCFA) are characterized by shorter chain lengths and are taken up by the mitochondria in their neutral (nonesterified) form in a CPT-independent manner (Kerner and Hoppel, 2000). Moreover, this type of fatty acids can be readily oxidized inside the matrix because of the presence of a matrixassociated enzyme, which allows the activation and subsequent $\beta$-oxidation of MCFA (Fujino et al., 2001). Finally, mediumchain fatty acids are saturated fatty acids and thus not sensitive to lipid peroxidation. The lack of up-regulation of UCP3 when high amounts of these medium chain saturated fatty acids are given is entirely consistent with the hypothesis that UCP3 exports fatty acids anions from the matrix to prevent them from peroxidation. Finally, we recently found that UCP3-ablated mice are characterized by increased levels of intramuscular lipid peroxides, as would be expected when the potential protective function of UCP3 is eliminated (Hoeks et al. 2006), although this finding could as well be explained by a direct effect of UCP 3 on ROS production as suggested by Brand et al. 2002 (Echtay et al., 2002; Echtay et al., 2003).

\section{UCP3 may prevent lipid peroxidation by acting as a lipid peroxide exporter}

In 2003, Goglia and Skulachev postulated the hypothesis that UCP3 operates as a carrier of fatty acid peroxide anions (Goglia and Skulachev, 2003). As explained previously, reactive oxygen species, originating from oxidative metabolism in the mitochondrial matrix, can peroxidize fatty acids thereby initiating a chain reaction resulting in the formation of highly reactive lipid peroxides (Yagi, 1987). The matrix is the most vital part of mitochondria, containing mtDNA and RNA and numerous enzymes, catalyzing essential metabolic reactions, some of which are highly sensitive to ROS (Gardner, 
1997; Skulachev, 1998). The hypothesis by Goglia and Skulachev (Goglia and Skulachev, 2003) states that UCP3 functions to prevent potentially damaging accumulation of fatty acid peroxides in the inner leaflet of the inner mitochondrial membrane. It is assumed that UCP3 is capable of translocating fatty acid peroxides, like fatty acid anions, from the inner membrane leaflet to the outer membrane leaflet. The chemical nature of fatty acid peroxides (which are, in contrast to neutral fatty acids, unable to flip-flop) makes that the peroxides, transported to the outer leaflet by UCP3, will remain in this leaflet while the inner leaflet is purified from these compounds (Goglia and Skulachev, 2003). In this way, potentially toxic fatty acid peroxides are removed from the matrix side of the membrane, thereby protecting mitochondrial DNA, RNA and critical metabolic enzyme systems. This hypothesis indeed is compatible with the numerous physiological observations reporting that UCP3 is up regulated under high free fatty acid conditions, since the probability of fatty acid peroxidation must increase with fatty acid concentration. Although the faith of the exported fatty acid peroxides that would accumulate in the outer leaflet remains to be elucidated, the intermembrane space is less vulnerable to oxidative damage since it does not contain nucleic acids or essential metabolic systems and limited amounts of enzymes (Goglia and Skulachev, 2003). Most of these intermembrane space enzymes are much more resistant to ROS, while some of them even scavenge reactive oxygen species (i.e. cytochrome $c$ ) (Skulachev, 1998).

Taken together, the hypotheses of Goglia and Skulachev as well as our hypothesis provide a more detailed explanation for a putative protective role of UCP3 against lipid-induced mitochondrial damage and would predict that lack of UCP3 results in the peroxidation of fatty acids in the vicinity of the mitochondrial matrix. Such function nicely fits with previous observations that UCP3 is highly expressed in skeletal muscles that have a low capacity to oxidize fatty acids and are prone to accumulate fat (such as glycolytic type $2 b$ muscle fibres), whereas muscle with a very high oxidative capacity (like fat oxidative type 1 muscle fibres and cardiac muscle) need less UCP3 (Hoeks et al., 2003; Hesselink et al., 2001). In our view, it is less well evident why highly fat oxidative muscles would express lowest amounts of UCP3 if the major role of UCP3 would be the regulation of ROS production.

Taken together, UCP3 seems to be involved in the protection of mitochondria against ROS mediated lipotoxicity, but the exact mechanism of action remains to be elucidated.

\section{Can UCP3 explain the lipid-induced mitochondrial damage observed in diabetes and aging?}

Although the exact function of UCP3 is not yet entirely unravelled, all current hypotheses predict that lack of UCP3 would result in increased lipid peroxidation and potentially damage to mitochondrial DNA, RNA and proteins. Most direct evidence for this comes from mice lacking UCP3 who have indeed been characterized by increased levels of oxidative damage to proteins, lipids and DNA (Brand et al., 2002). Interestingly, increased levels of muscular lipid peroxides were found in the insulin-resistant state (Russell et al., 2003) and given that skeletal muscle mitochondria from type 2 diabetic patients are smaller, are more damaged and display a reduced functional capacity (Kelley et al., 2002; Petersen et al., 2004; Petersen et al., 2003), it is tempting to speculate that defective UCP3 function may be responsible. Interestingly, we indeed showed that skeletal muscle mitochondria of type 2 diabetic patients are characterized by a $50 \%$ reduction in $\mathrm{UCP} 3$ protein content (Schrauwen et al., 2001b). In addition, we recently observed that a similar reduction in UCP3 protein expression could already be observed in the pre-diabetic state, suggesting that low UCP3 may indeed be causally related to the development of mitochondrial dysfunction in this disorder. In that context the parallel with aging is interesting, as also elderly are characterized by mitochondrial dysfunction (Petersen et al., 2003), accumulation of ROS-induced mutations in control sites of mitochondrial DNA replication (Michikawa et al., 1999), and a reduction of UCP3 levels (Kerner et al., 2001).

In conclusion, mitochondrial uncoupling proteins may have a role in mild uncoupling and regulation of mitochondrial ROS production. The skeletal muscle isoform of the uncoupling protein family, UCP3, seems to have a specific function under conditions of high fatty acid availability, either as a direct regulator of ROS production or as an exporter of fatty acid anions and/or peroxides from the mitochondrial matrix, thereby specifically protecting fatty acids from ROS-induced oxidative damage. The reduction of UCP3 protein with aging and diabetes, both conditions characterized by increased levels of oxidative damage to lipids and proteins and reduced mitochondrial function, may suggest involvement of UCP3 in the aetiology of mitochondrial dysfunction, but further studies are needed to elucidate the exact role of UCP3 in human physiology.

\section{References}

Boveris, A., Oshino, N., Chance, B., 1972. The cellular production of hydrogen peroxide. Biochem. J. 128 (3), 617-630.

Brand, M.D., Pamplona, R., Portero-Otin, M., Requena, J.R., Roebuck, S.J., Buckingham, J.A., et al., 2002. Oxidative damage and phospholipid fatty acyl composition in skeletal muscle mitochondria from mice underexpressing or overexpressing uncoupling protein 3. Biochem. J. $368(\mathrm{Pt} 2)$, 597-603.

Echtay, K.S., Roussel, D., St. Pierre, J., Jekabsons, M.B., Cadenas, S., Stuart, J.A., et al., 2002. Superoxide activates mitochondrial uncoupling proteins. Nature 415 (6867), 96-99.

Echtay, K.S., Esteves, T.C., Pakay, J.L., Jekabsons, M.B., Lambert, A.J., Portero-Otin, M., et al., 2003. A signalling role for 4-hydroxy-2nonenal in regulation of mitochondrial uncoupling. EMBO J. 22 (16), 4103-4110.

Fujino, T., Takei, Y.A., Sone, H., Ioka, R.X., Kamataki, A., Magoori, K., et al., 2001. Molecular identification and characterization of two medium-chain acyl-CoA synthetases, MACS1 and the Sa gene product. J. Biol. Chem. 276 (38), 35961-35966.

Gardner, P.R., 1997. Superoxide-driven aconitase FE-S center cycling. Biosci. Rep. 17 (1), 33-42. 
Goglia, F., Skulachev, V.P., 2003. A function for novel uncoupling proteins: antioxidant defense of mitochondrial matrix by translocating fatty acid peroxides from the inner to the outer membrane leaflet. FASEB J. 17 (12), $1585-1591$.

Hamilton, J.A., Kamp, F., 1999. How are free fatty acids transported in membranes? Is it by proteins or by free diffusion through the lipids? Diabetes 48 (12), 2255-2269.

Hesselink, M.K., Keizer, H.A., Borghouts, L.B., Schaart, G., Kornips, C.F., Slieker, L.J., et al., 2001. Protein expression of UCP3 differs between human type 1, type $2 \mathrm{a}$, and type $2 \mathrm{~b}$ fibers. FASEB J. 15 (6), 1071-1073.

Hoeks, J., Hesselink, M.K., van Bilsen, M., Schaart, G., van der Vusse, G.J., Saris, W.H., et al., 2003. Differential response of UCP3 to medium versus long chain triacylglycerols; manifestation of a functional adaptation. FEBS Lett. 555 (3), 631-637.

Hoeks, J., Hesselink, MK., Sluiter, W., Schaart, G., Willems, J., Morrisson, A., Clapham, J.C., Saris, W.H., Schrauwen, P., 2006. The effect of high-fat feeding on intramuscular lipid and lipid peroxidation levels in UCP3ablated mice. FEBS Lett. 580 (5), 1371-1375.

Jezek, P., Orosz, D.E., Modriansky, M., Garlid, K.D., 1994. Transport of anions and protons by the mitochondrial uncoupling protein and its regulation by nucleotides and fatty acids. A new look at old hypotheses. J. Biol. Chem. 269 (42), 26184-26190.

Kelley, D.E., Simoneau, J.A., 1994. Impaired free fatty acid utilization by skeletal muscle in non-insulin-dependent diabetes mellitus. J. Clin. Invest. 94 (6), 2349-2356.

Kelley, D.E., He, J., Menshikova, E.V., Ritov, V.B., 2002. Dysfunction of mitochondria in human skeletal muscle in type 2 diabetes. Diabetes 51 (10), 2944-2950

Kerner, J., Hoppel, C., 2000. Fatty acid import into mitochondria. Biochim. Biophys. Acta 1486 (1), 1-17.

Kerner, J., Turkaly, P.J., Minkler, P.E., Hoppel, C.L., 2001. Aging skeletal muscle mitochondria in the rat: decreased uncoupling protein-3 content. Am. J. Physiol. Endocrinol. Metab. 281 (5), E1054-E1062.

McGarry, J.D., 2002. Banting lecture 2001: dysregulation of fatty acid metabolism in the etiology of type 2 diabetes. Diabetes 51 (1), 7-18.

Michikawa, Y., Mazzucchelli, F., Bresolin, N., Scarlato, G., Attardi, G., 1999. Aging-dependent large accumulation of point mutations in the human mtDNA control region for replication. Science 286 (5440), 774-779.

Perseghin, G., Scifo, P., De Cobelli, F., Pagliato, E., Battezzati, A., Arcelloni, C., et al., 1999. Intramyocellular triglyceride content is a determinant of in vivo insulin resistance in humans: a $1 \mathrm{H}-13 \mathrm{C}$ nuclear magnetic resonance spectroscopy assessment in offspring of type 2 diabetic parents. Diabetes 48 (8), 1600-1606.

Petersen, K.F., Befroy, D., Dufour, S., Dziura, J., Ariyan, C., Rothman, D.L., et al., 2003. Mitochondrial dysfunction in the elderly: possible role in insulin resistance. Science 300 (5622), 1140-1142.

Petersen, K.F., Dufour, S., Befroy, D., Garcia, R., Shulman, G.I., 2004. Impaired mitochondrial activity in the insulin-resistant offspring of patients with type 2 diabetes. N. Engl. J. Med. 350 (7), 664-671.

Russell, A.P., Gastaldi, G., Bobbioni-Harsch, E., Arboit, P., Gobelet, C., Deriaz, O., et al., 2003. Lipid peroxidation in skeletal muscle of obese as compared to endurance-trained humans: a case of good vs. bad lipids? FEBS Lett. 551 (1-3), 104-106.

Sastre, J., Pallardo, F.V., Vina, J., 2000. Mitochondrial oxidative stress plays a key role in aging and apoptosis. IUBMB Life 49 (5), 427-435.

Schrauwen, P., Saris, W.H., Hesselink, M.K., 2001a. An alternative function for human uncoupling protein 3: protection of mitochondria against accumulation of nonesterified fatty acids inside the mitochondrial matrix. FASEB J. 15 (13), 2497-2502.

Schrauwen, P., Hesselink, M.K., Blaak, E.E., Borghouts, L.B., Schaart, G., Saris, W.H., et al., 2001b. Uncoupling protein 3 content is decreased in skeletal muscle of patients with type 2 diabetes. Diabetes 50 (12), 2870 2873.

Schrauwen, P., Hoeks, J., Schaart, G., Kornips, E., Binas, B., Van De Vusse, G.J., et al., 2003. Uncoupling protein 3 as a mitochondrial fatty acid anion exporter. FASEB J. 17 (15), 2272-2274.

Skulachev, V.P., 1991. Fatty acid circuit as a physiological mechanism of uncoupling of oxidative phosphorylation. FEBS Lett. 294 (3), 158-162.

Skulachev, V.P., 1996. Role of uncoupled and non-coupled oxidations in maintenance of safely low levels of oxygen and its one-electron reductants. Q. Rev. Biophys. 29 (2), 169-202.

Skulachev, V.P., 1998. Cytochrome $\mathrm{c}$ in the apoptotic and antioxidant cascades. FEBS Lett. 423 (3), 275-280.

Turrens, J.F., 1997. Superoxide production by the mitochondrial respiratory chain. Biosci. Rep. 17 (1), 3-8.

Vidal-Puig, A.J., Grujic, D., Zhang, C.Y., Hagen, T., Boss, O., Ido, Y., et al., 2000. Energy metabolism in uncoupling protein 3 gene knockout mice. J. Biol. Chem. 275 (21), 16258-16266.

Yagi, K., 1987. Lipid peroxides and human diseases. Chem. Phys. Lipids 45 (2-4), 337-351. 